\title{
Toxigenic Corynebacterium ulcerans infection in a veterinary student in London, United Kingdom, May 2010
}

J Taylor ${ }^{1}$, M Saavedra-Campos (Maria.Saavedra-Campos@hpa.org.uk)ํ, D Harwood², G Pritchard³, N Raphaely4, S Kapadia5, A Efstratiou ${ }^{6}$, J White 7 , S Balasegaram ${ }^{1}$

1. North East and North Central London Health Protection Unit, London, United Kingdom

2. Veterinary Laboratories Agency, Itchen Abbas, Winchester, United Kingdom

3. Veterinary Laboratories Agency, Rougham Hill, Bury St Edmunds, Suffolk, United Kingdom

4. Thames Valley Health Protection Unit, Didcot, United Kingdom

5. Essex Health Protection Unit, Witham, United Kingdom

6. Streptococcus and Diphtheria Reference Unit, Health Protection Agency Centre for Infections, London, United Kingdom

7. Immunisation, Hepatitis and Blood Safety Department, Health Protection Agency Centre for Infections, London, United Kingdom

Citation style for this article:

Taylor J, Saveedra-Campos M, Harwood D, Pritchard G, Raphaely N, Kapadia S, Efstratiou A, White J, Balasegaram S. Toxigenic Corynebacterium ulcerans infection in a veterinary student in London, United Kingdom, May 2010. Euro Surveill. 2010;15(31):pii=19634. Available online: http://www.eurosurveillance.org/ViewArticle. aspx?Articleld $=19634$

Article published on 5 August 2010

We report on a case of toxigenic Corynebacterium ulcerans infection in a fully immunised veterinary student, investigated in London, United Kingdom, in May 2010. There was no ongoing transmission in human contacts. Possible animal sources were identified.

\section{Introduction}

Diphtheria can result in an acute infection of the upper respiratory tract or a cutaneous lesion. It is caused by three toxin-producing Corynebacterium species: $C$. diphtheriae responsible for epidemic disease, C. ulcerans and, more rarely, C. pseudotuberculosis, the last two being zoonotic infectious agents $[1,2]$.

In the United Kingdom (UK) between 2000 and 2009, 43 isolates of toxigenic corynebacteria were identified in England and Wales, 27 of which were C. ulcerans. Three unvaccinated individuals presented with clinical symptoms typical of classic diphtheria, but most had milder respiratory infections (sore throat or tonsillitis) and had been either partially or fully immunised $[3,4]$.

Cattle are a documented reservoir for C. ulcerans and risk factors for human infection with this species include contact with these and other farm animals [5]. Less commonly, $C$. ulcerans can also be spread through consumption of unpasteurised milk and unpasteurised milk products [6]. More recently, contact with dogs and other companion animals has also been proposed as a source of infection [7-9]. Despite limited evidence of person-to-person spread of $C$. ulcerans, this is a potential route of transmission $[6,10]$. It is therefore recommended that the public health response following isolation of toxigenic $C$. ulcerans from a human case be the same as that for toxigenic $C$. diphtheriae [6].

A primary course of diphtheria-containing vaccine is included in the UK's vaccination schedule and is given at the age of two, three and four months, plus a preschool booster between the age of three years four months and five years. This is followed by a booster between the age of 13 and 18 years [11].

\section{Case report}

A 20-year-old veterinary student in London, United Kingdom, with no significant medical history, experienced four to five weeks of recurrent sore throat and tonsillitis unresponsive to a full course of penicillin towards the end of March 2010. As symptoms remained, the case was reviewed by the family doctor and a throat swab was taken from white tonsillar lesions on 10 May 2010.

The local Health Protection Unit (HPU) was notified by a hospital microbiology registrar on 17 May 2010 that the throat swab had grown C. ulcerans. A second throat swab, taken on 18 May, when the case was still symptomatic was then sent to the Streptococcus and Diphtheria Reference Unit for primary culture and toxigenicity testing. The case was clinically assessed by the family doctor and, in consultation with the HPU and microbiology registrar, a course of erythromycin was started on 18 May 2010. The sample was confirmed as toxigenic on 21 May 2010.

The case had received a full recommended UK course of immunisation with diphtheria toxoid, plus a booster at 14 years. The family doctor was advised by the HPU to offer a convalescent diphtheria booster vaccination as part of the routine management of the case.

In-depth discussions with the case confirmed that there was no exposure to unpasteurised milk and no recent overseas travel. 
As part of a veterinary medicine undergraduate course, the case had been in recent contact with animals on two separate farming placements. The date of symptom onset was determined to be during a lambing placement at a farm in the last two weeks of March 2010.

\section{Risk assessment of human contacts}

All close contacts were followed up as indicated by national guidelines [6].

The risk assessment identified four household contacts sharing college accommodation, two close contacts and a partner. One household contact had mild symptoms (sore throat). Four of these seven contacts had records of a full course of immunisation for diphtheria, while the others had no record of past immunisations against diphtheria (including the contact with mild symptoms).

Three family members were also identified as contacts, as the case had stayed with family during the farm placements. One family member had developed a sore throat after the case's onset of symptoms. A complete immunisation record was found for two of these family contacts, including the one who developed a sore throat.

Throat swabs were taken from all of these contacts, who were also provided with prophylaxis and advised on signs and symptoms of the infection by their family doctor. Family doctors were advised by the HPU to offer a booster vaccination if none had been received in the previous 12 months. All swabs were found to be negative for C. ulcerans.

One further asymptomatic contact who accompanied the case during the lambing placement (and was therefore subject to the same potential exposure) was also identified. As all samples of contacts had been negative for C. ulcerans, a throat swab was taken, but no prophylaxis or vaccination given. This throat swab was also negative.

\section{Risk assessment of animal contacts}

A detailed risk assessment of the two farming placements was undertaken by the local HPU, in close collaboration with the Veterinary Laboratories Agency, to determine if a likely source of infection could be identified and if there was any ongoing risk to the public or farm owners and workers.

The second placement commenced after symptom onset and was therefore disregarded as a possible source of infection. The first was a lambing placement on a farm with 800 sheep. However, enquiries to the farm's veterinarian established that the usual standard of animal health and hygiene on the farm was high, there were no reported health problems in the sheep flock during lambing and there were no dogs (working or pets) on the farm. The farm owners and workers were all reported to be fit and well and their contact with the sheep and lambs was determined to be minimal outside lambing season, which had ended some weeks before the case was notified to the HPU. Moreover, this farm is not open to the public. Consequently, the ongoing risk to human health was assessed to be very low and no further investigations were deemed to be necessary.

The case had been in close contact with a number of domestic animals (dogs, cat, rabbit and chickens) during the same period as the lambing placement. However, none of these were reported to have exhibited any clinical signs suggestive of $C$. ulcerans infection and, in view of the time lapse and large number of potential exposures, it was not feasible to undertake any animal sampling [7].

\section{Discussion}

Infection with a toxigenic strain of $C$. diphtheriae or C. ulcerans can cause serious illness in unvaccinated individuals: five deaths from diphtheria have been recorded in the UK since 1986, three of them due to C. ulcerans infection [10]. The number of clinical cases is small and there have been no previous toxigenic corynebacterial isolates from veterinarians. There is no booster vaccination for the general adult population, and the severity of the infection can be especially serious in elderly people in contact with pets $[12,13]$.

While the source of infection for this case was not proven, the lambing farm or domestic animals were considered to be the most likely sources. Domesticated animals have been implicated as potential reservoirs of $C$. ulcerans and the organism is a recognised commensal in several animal species, usually without overt clinical signs, although it has been associated with nasal discharge in cats [5-8]. Furthermore, the antibiotics licensed to eliminate the pathogen in humans are often not licensed for animals. As discussed previously by other authors, a number of difficult issues arise in attempting to eliminate subclinical zoonotic infections from healthy animals for perceived public health reasons [7]. It may be more appropriate to ensure that occupationally exposed groups, such as veterinary students, are appropriately immunised.

The case presented here had been fully immunised against diphtheria. This probably explains the relatively mild presentation of symptoms, as the vaccine provides protection against the effects of toxin produced by the bacteria. Most UK laboratories will only screen for corynebacteria if there is a clinical indication of diphtheria and/or contact with a known case, which suggests that other mild diphtheria cases may be missed. Indeed, the delay in initial diagnosis of this case was due to the low level of clinical suspicion.

\section{Conclusions}

Toxigenic C. ulcerans infection remains rare, but it can be fatal, especially among those who are not 
immunised. As animal sources can be difficult to identify and control, maintenance of high vaccination coverage among the child and adult populations is essential.

\section{Acknowledgements}

We would like to acknowledge the primary care doctors of the case and all contacts, as well as staff at University College London Hospital, the Streptococcus and Diphtheria Reference Unit and Health Protection Agency (HPA) local and regional services who supported contact tracing. Finally, we would like to thank the case who kindly consented to this article being written.

\section{References}

1. Hawker J, Begg N, Blair I, Reintjes R, Weinberg J. Communicable disease control handbook. 2nd ed. Oxford: Blackwell Publishing: 2005.

2. Perkins S, Cordery R, Nixon G, Abrahams A, Andres J, White $J$, et al. Investigations and control measures following a non-travel-associated case of toxigenic Corynebacterium diphtheriae, London, United Kingdom, December 2009January 2010. Euro Surveill. 2010; 15(16): pii=19544. Available from: http://www.eurosurveillance.org/ViewArticle. aspx?Articleid $=19544$

3. Health Protection Agency (HPA). Isolates of toxigenic corynebacteria England and Wales 1986-2009. London: HPA. 14 May 2010. Available from: http://www.hpa.org.uk/webw/ HPAweb\&HPAwebStandard/HPAweb_C/1195733776809 $? p=1191942153427$

4. Health Protection Agency (HPA). Diphtheria in England and Wales: 2005-2006. Weekly infection report: 2007; 1(39). Available from: http://www.hpa.org.uk/hpr/archives/2007/ hpr3907.pdf

5. Legget BA, De Zoysa A, Abbott YE, Leonard N, Markey B, Efstratiou A. Toxigenic Corynebacterium diphtheriae isolated from a wound in a horse. Vet Rec. 2010;166(21):656-7.

6. Bonnet JM, Begg NT. Control of diphtheria: guidance for consultants in communicable disease control. Commun Dis Public Health. 1999;2(4):242-9.

7. Hogg RA, Wessels J, Hart J, Efstratiou A, De Zoysa A, Mann G, et al. Possible zoonotic transmission of toxigenic Corynebacterium ulcerans from companion animals in a human case of fatal diphtheria. Vet Rec. 2009;165(23):691-2.

8. De Zoysa A, Hawkey PM, Engler K, George R, Mann G, Reilly W, et al. Characterization of toxigenic Corynebacterium ulcerans strains isolated from humans and domestic cats in the United Kingdom. J Clin Microbiol. 2005;43(9) 4377-81.

9. Lartigue MF, Monnet X, Le Fléche A, Grimont PA, Benet $J$, Durrbach A, et al. Corynebacterium ulcerans in an immunocompromised patient with diphtheria and her dog. I Clin Microbiol. 2005;43(2):999-1001.

10. Wagner KS, White JM, Crowcroft NS, De Martin S, Mann G, Efstratiou A. Diphtheria in the United Kingdom, 1986-2008: the increasing role of Corynebacterium ulcerans. Epidemiol Infect. Forthcoming 2010.

11. Department of Health (DH). Routine childhood immunisations from Spring 2010. London: DH. [Accessed 28 Jun 2010]. Available from: http://www.dh.gov.uk/prod_consum_dh/ groups/dh_digitalassets/@dh/@en/@ps/documents/ digitalasset/dh_114119.pdf

12. Bonmarin I, Guiso N, Le Fleche-Mateos A, Patey O, Patrick AD, Levy-Bruhl D. Diptheria: A zoonotic disease in France? Vaccine. 2009;27(31):4196-200.

13. Edmunds WJ, Pebody RG, Aggerback H, Baron S, Berbers G, Conyn-Van Spaendonck MA, et al. The sero-epidemiology of diphtheria in Western Europe. ESEN Project. European SeroEpidemiology Network. Epidemiol Infect. 2000;125(1):113-25. 